\title{
Outlining the Language Policy and Planning (LPP) in Fiji; Taking Directions From Fiji Islands Education Commission Report of 2000
}

\author{
Prashneel Ravisan Goundar ${ }^{1}$ \\ ${ }^{1}$ School of Communication, Language \& Literature, Fiji National University, Lautoka, Fiji \\ Correspondence: Prashneel Ravisan Goundar, School of Communication, Language \& Literature, Fiji National \\ University, P. O. Box 5529, Lautoka, Fiji.
}

Received: April 30, 2019 Accepted: June 4, $2019 \quad$ Online Published: June 7, 2019
doi: 10.5539/elt.v12n7p61
URL: https://doi.org/10.5539/elt.v12n7p61

\begin{abstract}
Language is something many individuals take for granted. It is usually when we discover that our language (or language variety) is different from and perhaps less valued than, the language of others or that our options are somehow limited, either because 'we do not speak/understand a language or language variety, or use it inappropriately or ineffectively in a particular context that we begin to pay attention to language'. This paper gives a sketch of Language Policy and Planning (LPP) which is becoming a well-researched field for many academics as well as postgraduate students. The article provides the latest pertinent information on Fiji's LPP, the linguistic background as well as the medium of instruction (MOI). It further deliberates on the recommendations from the Fiji Islands Education Commission Report of 2000 which is a well-articulated document that provides an overt grounding for LPP in the South Pacific.
\end{abstract}

Keywords: language policy, language planning, medium of instruction, Fiji, LPP, language issues

\section{Introduction}

Fiji is a multilingual, multiracial country situated in the South Pacific with various languages that make up the nation. Bordering both the Polynesian and Melanesian parts of the South Pacific, is Fiji with a number of dialects of Fijian (Geraghty, 1984) and a multiplicity of Indian languages: Hindi, Gujerati, Punjabi, Urdu, Telegu, Tamil, Malayalam (Mugler \& Lynch, 1996), and a number of minority languages, the most prominent being Rotuman. According to Mangubhai (2002), the choice of language $X$ as a medium of instruction or the language of initial literacy for all necessarily advantages the speakers of that language over the speakers of language Y. Furthermore, it is stated that this is a sociopolitical reality for which the solution or solutions are not simple. It is neither as simple as claiming that learners with language $Y$ background will necessarily underachieve in a school system, as other factors, such as, societal attitudes to the group and its language, and the power relationships contribute to the outcomes also (Cummins, 1986). These non-school-based factors need to be kept in mind in a discussion of language-in-education policy (Mangubhai, 2002).

The Fiji Education Commission Report (2000) infers, there is a plurality of knowledge and each knowledge system has a historical and cultural context. In Fiji's education system there are fragments of Fijian (iTaukei), Indo Fijian (Fijians of Indian decent) and other minority knowledge systems that have come from different cultural and political circumstances. During the colonial era the knowledge systems of Fijians, Indo Fijians and other minatory groups were subjugated. The report goes on to say that now, they are beginning to be reclaimed, partly through learning various languages and studying local historical experiences. English has become the dominant language in Fiji despite the three-language policy. The younger generation are unable to read the Devanagari Hindi script and iTaukei has no evolving written literature; both are serious concerns as indications are that both languages will be endangered vernaculars. Therefore, an urgent need arises to look into the language issues that Fiji is facing and develop a clear framework to outline the solutions.

Further, the past three decades has seen the rise in worldwide concerns about language endangerment, blamed mostly on globalization and the seemingly unstoppable spread of a few large international languages, 'chief among these English' (Ball, 2010). With the spread of English largely due to it being a language for business, governance and for academic excellence there is a threat to the existing languages in Fiji, which include iTaukei, Fiji Hindi, and other minority languages such as Tamil, Telugu, Malayalam, Rotuman, Chinese, to name a few. Further, Ball (2010) adds that the South Pacific has not escaped this trend, and indeed many of the earlier 
predictions by linguists and concerned educationalists, often based entirely on the demography of individual languages can; mean doom for the vast majority of languages in the region.

According to Professor Subramani (pers.Comm) of The University of Fiji 'there has not been any educational strategies employed to bring the three languages (English, Hindi, and iTaukei) to the same level which has resulted in an unequal development of languages'. The insightful comments by him are supported by the opinion of past policy makers. In 2005, there was a National Language debate in Fiji, during which the Minister for Education Taufa Vakatale stated 'If Indians in the country lost their language, there is a whole continent of people in India who would still have the language'. She further claimed 'in the whole world only 330,000 people know how to speak in Fijian (iTaukei) and if it is lost, there is nowhere it can be revived from, that is why the Fijian language is important to preserve' (Word Press, 2009). In light of the perspective of Ms. Vakatale, Professor Subramani (pers.Comm) emphasized in a discussion, that 'the iTaukei literature has not grown, if literature does not grow then the language does not grow'. The imbalance is a result of policy planners from the colonial era not being consistent in implementing language policies. According to Professor Subramani (pers.Comm) Fiji Hindi that evolved in the plantation is also becoming diasporic with uprooting of farmers. Furthermore, there are also a small number of speakers of Fiji Hindi, and very tiny literature in it.

A study conducted by Mangubhai and Mugler (2003) presented a historical review of the language policy in Fiji. The study reveals the domination of English language which is obviously because of Fiji being a past English colony (Shrestha, 2008). Furthermore, they conclude that the changes taking place in Fiji are due to people's interest as much as language planning by the government unlike in countries such as Iceland where the government has implemented a protectionist language policy to neutralize the threat of English (Hillmarsson-Dunn, 2006).

\section{Language Policy and Planning Study in Fiji}

Language forms the basis how of a society functions in its daily business, education and governance. Perry (2011, p. 4) defines language as the backbone of a society and claims it to be one of the major characteristics of being human. He further elaborates that without it we would not know the world as we know it today. Literally everything that humanity has achieved would not have taken place without language (Perry, 2011, p. 4). A crucial point that he highlighted is that significant strides have been made in applied linguistics research which has led to the improvement of teaching and learning of languages throughout the world. In order to contextualize the language situation in Fiji, it is essential to understand the linguistic landscape of Fiji and how widely debatable the language policies have been in the past. An in-depth analysis of the language varieties in Fiji was conducted by the Fiji Education Commission (2000).

The Commission's (2000) point of view on language policy is worth noting:

'Language policy is a relatively new area of planning in the history of the nation-state. In postcolonial, multilingual societies it is an even more recent type of decision making. Therefore, it is not surprising that many countries do not have any coherent language policy. Most decisions about language learning and teaching are made somewhat arbitrarily' (Fiji Education Commission, 2000, p. 290).

The commission mentioned Fijian, English, Standard Hindi (Shudh Hindi), Urdu, the South Indian Languages including Tamil, Telegu, as well as the minority languages such as Rotuman, Rabi, Kioa and Chinese. However, there has not been any significant recent research on these languages (publications, writings, music, films) and the speakers (Mangubhai \& Mugler, 2003). Therefore, this article will be filling the gap of the changes that have transpired as well as the issues within each language.

In Fiji, since the 1926 Review of Education Commission established the main language policy-the practice of instruction in the mother tongue in the first three years of primary school and thereafter English replacing the first language; there has not been a major shift in language policy (Fiji Education Commission, 2000, p. 290). For example, one of the language issues highlighted by the Education Commission of 2000 (p.290) is that the Ministry of Education's project of providing conversational Fijian and Hindi and the decision by individual school managements to introduce the teaching of Fijian (i-Taukei) to all students have not been very fruitful because these initiatives, though laudable, did not emanate from language planning and therefore, lacked political support, expertise and community involvement.

Additionally, a crucial issue that has existed since the colonial era is the promotion of English over other major languages in Fiji despite the Education Commission of 1969 emphasizing the need for education in the mother tongue. This could suggest that whatever was put in place post-independence has unofficially been changed and not followed. Subramani (Fiji Education Commission, 2000, p. 291) states 'there were many internal factors that 
enhanced the status of English, such as the need for a lingua franca in a multi-ethnic Fiji, the presence of many overseas teachers who did not know the local languages and divided loyalty within the respective communities towards Hindi and Fijian'.

\section{Medium of Instruction}

Religious organizations in Fiji have always had a major influence in the education sector; these include the TISI Sangam, Arya Pratinidhi Sabha, Fiji Muslim League, Fiji Sikh Society, Gujarat Society, Methodist Church of Fiji, Sanatan Dharam Pratinidhi Sabha and Institute of Fijian language and Culture. Mugler (1996, p. 276) explains that as early as 1910s Indians in Fiji started their own schools, spurred on by the colonial governments neglect of their children's education, attested by the 1911 census rates for literacy in any language: $86 \%$ for Europeans, 52.8\% for Fijians and a paltry 9.4\% for Indians. By the 1920s a substantial number of schools had been set up for Indian children, in which Hindi and other Indian languages such as Urdu, Tamil, Telugu, and later Gujarati, were used as languages of instruction (Mugler, 1996, p. 276).

As the colonial government gradually took over control of schools from religious organisations, the use of various vernaculars as languages of instruction decreased (Mugler, 1996, p. 276). The role of English increased dramatically as a consequence of a 1916 Education Ordinance policy whereby the government provided financial aid to independent schools on the condition that they taught some English (Mangubhai, 1984). The 1926 policy was that vernaculars would be used in primary education, however English would be used as soon as students were intellectually prepared (Roberts, 2007). The 1926 education policy, with the initial mother-tongue instruction being phased to English by Class 4 has influenced Fiji's 'transitional education system', a term which refers to a system where students are expected to transition from their mother tongue to the language of instruction (Nicholls, 2014). Fiji primary schools are run by religious, community and parent-teacher committees who determine and make decisions on the language of instruction used for the schools (Shameen, 2002, p. 390). This implies that they decide whether to follow the transitional policy or not. Similarly, Mugler (1996, p. 282) shares; 'reliance on vernaculars an informal languages of instruction is facilitated in Fiji, particularly in rural areas, by the traditional segregation of "Fijian" and "Indian" schools, which to a certain extent persists to this day in spite of efforts in recent years' at making schools "multiracial". It appears that the 1926 policy may be in place but it is not being followed to the letter. There seems to be some misperception on the actual policies that need to be used.

According to Mugler (1996, pp. 283-284) the fact that teachers are left to their own devices may well be the most pragmatic way to deal with the issue of language diversity in the classroom, but the lack of a clear policy and of adequate training and the limitations of current materials must surely limit the efficacy of teaching, whether it is teaching the vernacular as a subject or using it as a medium of instruction (MOI). The 1969 Report of the Fiji Education Commission which examined the system of education highlighted that English be the medium of instruction from Grade 4, which was put into effect when Fiji became independent, has been the guiding policy up to the present time (Nicholls, 2014).

\section{Language Provisions in the Constitution}

The past constitutions of Fiji have tried to accommodate all languages in the country as illustrated in Table 1. The latest constitution of 2013 has had more provisions added to this particular component. Even though the 2013 Constitution recognizes the main languages (see Table 1) as equal in terms of status, use and function; the reality is that English has gained more prominence in terms of the official language used in tertiary institutions, the government, in business and others. Moreover, the two main languages (Fijian and Hindi) comprise of their own standards varieties. For example, not all native Fijians speak the Bauan dialect daily and Fijians of Indian descent use either Fiji Hindi, Tamil, Telegu, Malayalam, Gujarati, Urdu or Punjabi. Therefore, the three language policy of 1926 is undermining the minority languages which come under the two main (Fijian and Hindi) language category which has created an imbalance.

Table 1. Fiji's language provisions in the constitutions

\begin{tabular}{ll}
\hline Year & Policy \\
\hline & The 2013 Constitution recognises that "all Fijians are united by common and equal citizenry". It gives \\
equal status to languages of the "i-Taukei, Rotuman, descendants of labourers from British India (Fiji \\
Indians) and Pacific Islanders and settlers as well as migrants" (Constitution of the Republic of Fiji, \\
2013, p. 1).
\end{tabular}


The 1997 Constitution recognises that "Fiji is a multilingual state and that the main languages (Fijian,

1997 Hindi and English) are equal in terms of status", use and function (Fiji Education Commission, 2000, p. 291).

"English, Fijian and Hindi have official status", while no national language is specified. Furthermore,

1990 the constitution states that "the official language of Parliament shall be English, but any member of either House may address the Chair in the House of which he is a member in Fijian or Hindustani" (Mugler, 1996, p. 273).

\section{Discussions}

\subsection{LPP Recommendations from the Fiji Islands Education Commission of 2000}

In 2000, the People's Coalition Government under the leadership of Prime Minister Mr. Mahendra Pal Chaudhry and the Minister of Education Hon. Pratap Chand established an Education Commission. The first Education Commission was the 1969; Fiji Education Commission: Education for Modern Fiji. The year 2000 Education commission produced; Learning Together: Directions for Education in the Fiji Islands. Whilst the consultation process was being carried out throughout Fiji by the capable team of the Education Commission, on 19 May 2000 a civilian coup led by George Speight took place. This was the third coup in Fiji's history as there were two other coups in 1987. The events of 19 May 2000 lasted for 56 days as the cabinet members were held hostage in the parliament complex. Even though the commission's work was interrupted by the 2000 Civilian coup, the exercise still produced one of the most unbiased and well researched report which looks at various issues such as the levels of education (Primary, Secondary and Tertiary), the quality of education, Early Childhood Education, curriculum and assessment, Special Education, Language Policy and Planning (LPP) and other pivotal issues.

The consultation process had to be aborted due to the danger to the lives of its members. The chair had to flee the country for safety reasons soon after the events of May 2000 coup (Professor Subramani, per comm). The report was supposed to be implemented at the end of the process. However, after the change in governments the successors did not endorse it as it was initiated by the People's Coalition Government (Professor Subramani, per comm). In the research carried out by the Fiji Islands Education Commission of 2000, through interview process and based on the narratives provided in the consultation process; six key observations were made for considerations on Language policy and planning in Fiji to be taken up by policy makers. The following are the six observations for consideration (in italics) and the notes below it indicate the status of each recommendation presently.

1. 'All languages should be accorded equal status. This goes with the principle of giving equal opportunities to all students from different ethnic backgrounds. At present, the languages are unequally placed for historical and economic reason'. (Fiji Island Education Commission Report, 2000, p. 298).

Past constitutions have shared a similar sentiment, however this has not been fulfilled as of yet. The minority languages such as Chinese, Tamil, Telegu, Tuvaluan and Routman do not have expert educators or any literature developed for teaching. English is dominating the minority languages as it is used for official purposes and is the most common medium of instruction especially in urban areas.

2. 'Parents have the right to educate their children in their mother tongue. The most widely recognised value of multilingual education is the encouragement it gives different ethnic groups to improve and maintain the knowledge of their mother tongue. The concept of mother tongue should be redefined, taking into consideration regional variations. The principle that one regional variant is as good as another should be upheld. For Fijians in the west, the mother tongue is their own dialect, and standard Fijian should be regarded as a second language for them. In this regard, it should be noted that there are many examples in the world of persons with fluency in a particular regional dialect possessing a high level of command in the standard version'. (Fiji Island Education Commission Report, 2000, p. 298).

This rule is still followed to some extent as the 1926 policy of teaching L1 for the first three years of primary school and transitioning into English as a medium of instruction from the fourth year. However, the report is correct in stating that mother tongue needs to be refined in Fiji. For example, Fiji Hindi is not the L1 for all Fiji Indians, their L1 includes Gujarati, Punjabi, Tamil, Telegu, Malayalam, Bhojpuri. Fiji Hindi becomes the lingua franca for the Indo-Fijian majority and not the L1.

"For the vast majority of Indo-Fijians the mother tongue is Fiji Hindi. Fiji Hindi should be recognised as a distinct language with its own grammar; eventually it will have its own literature. Standard Hindi should be 
introduced as a subject in the post-primary curriculum and studied in relation to Fiji Hindi. The same should apply to standard Fijian. Any language policy that is formulated should support students' self-esteem and their respect for the language of their family and community". (Fiji Island Education Commission Report, 2000, p. 298).

This was taken up by the Bainimarama Government in 2007 by the Ministry of Education. However, till date it has not been formalised. Even at university level students can graduate with a degree in Standard Hindi and not in Fiji Hindi. Conversational Hindi which is being taught at the universities is only on Standard Hindi and not contextualised with Fiji's actual language usage. There is little literature available for teaching purposes, no dictionary or grammar has been developed to date. One of the few works that does exist is a novel published by Subramani in 2001 titled Dauka Puran which was a seminal work written in Fiji Hindi.

3. 'The teaching of Fijian from pre-school to the tertiary level, preparation of qualified teachers to teach Fijian, research and scholarship and encouragement of publication and literary activities in the language should be given high priority in the allocation of resources. It is a great concern to the Commission that qualified teachers in Fijian are almost non-existent, and very few students are attracted to Fijian studies at the University of the South Pacific. Equally disconcerting is the fact that, even though the 1969 Education Commission stressed the value of local literatures, writing in Fijian (fiction, poetry, plays) is still at a very rudimentary stage. There is a rich tradition of oral literature that ought to be adopted for use in the curriculum. The existence of this oral tradition and literature is a reminder that oracy should not be neglected in the curriculum, Fijian culture is characterised by its orature'. (Fiji Island Education Commission Report, 2000, p. 298).

It appears that Fiji still lacks adequate literature in the i-Taukei language. Rarely is any writing competition or oratory contest organised between primary or high schools or even in tertiary level competition in the i-Taukei language. Not enough is being done to promote the language with little literature or translations available in the market. New plays or movies have not been produced with very little promotion in national media.

4. 'The teaching of English should remain a major goal in the multilingual programme. Where there is a limited exposure to English and pupils have little or no knowledge of English before entering the school system, more specialists in teaching English as a Second Language or foreign language should be appointed so that students can benefit from greater professional attention'. (Fiji Island Education Commission Report, 2000, pp. 298-299).

'The term English as a second language is used to differentiate the teaching of English to students who are not native speakers of the language from classes for English-speaking pupils. For many students in Fiji, the vernacular language is their first language and English the second language. In urban areas, English is present in the everyday life of children; some speak both English and their mother tongue with equal fluency. However, for rural children, English is not part of their language environment and learning it would be like learning a foreign language such as Japanese or French'. (Fiji Island Education Commission Report, 2000, p. 299).

'Teacher training in English as as second or foreign or international language should form a major component of multilingual education. Tertiary institutions should ensure that all teachers, not only those who teach languages, have a general understanding of the problems of learning and teaching in a second or a foreign language. There ought to be greater cooperation among language teachers in the teacher training institutions for the purpose of research into multilingualism and teaching of a second/foreign language. There are not many specialists in Fiji in either multilingual, multicultural education or teaching a second/ foreign language'. (Fiji Island Education Commission Report, 2000, p. 299).

The University of Fiji has recently taken steps to address this issue. Two programmes were introduced in Teaching English as a Second Language (TESL) in 2011 and in 2013. The Post Graduate Diploma in TESL (http://www.unifiji.ac.fj/postgraduate-diploma-in-teaching-english-as-a-second-language/) was introduced in 2011 by Associate Professor Clifford Benson and later the Master of Arts (TESL) degree was developed by him and Mrs. Minakshi Maharaj in 2013. The courses look at second language acquisition, language awareness and issues, linguistics, socio-linguistics, teaching the four skills in TESL, teaching methodologies in second language, research topics/thesis in TESL and more.

5. 'The language policy in Fiji should recognise and promote the philosophy and practice of multilingualism. Language planning ought to deal with its complexities, bearing in mind the need to balance the dual objectives of national cohesion and linguistic diversity. An important policy change that is recommended in this Report (2000) is the active development of multilingual, multicultural education at all levels of the school system. There ought to be a shift away from transitional bilingualism, intended to provide pupils with instruction in their mother tongue until they can move into an all-English curriculum, towards active bilingualism, that is, maintenance and fuller development of the mother tongue while competence in English is being built' (Fiji 
Island Education Commission Report, 2000, p. 299). 'The problem with transitional bilingualism is that it may create an unstable language situation where students are not competent in either language. However, when students are fully literate in the first language or the mother tongue, and are capable of second language. A greater degree of bilingualism will be fostered if students continue to learn both their mother tongue and English right up to the end of primary school. The mother tongue should not be abandoned altogether after that but offered as a subject up to tertiary level. It would be an added advantage if students learn some subjects through their mother tongue at the secondary school level' (Fiji Island Education Commission Report, 2000, p.300). 'Programmes in conversational Fijian and Hindi and some of Fiji's minority languages (Rotuman, Urdu, Chinese, Tamil) should be developed and be available at all levels of the school system. Conversational language programmes in Fijian and Hindi should be compulsory up to Form 5. If enrolment is voluntary, competition from other subjects will push them to the periphery of the school curriculum. Skilled personnel from local communities could be recruited and trained to teach these programmes. Some peer group teaching is also possible and should be encouraged' (Fiji Island Education Commission Report, 2000, p. 300).

The last policy on language was in 1926 and since then there has been no policy to incorporate all the languages in Fiji. The idea of the colonial government of having vernacular as the medium of instruction for the first three years of primary schooling is argued by this recommendation. There is no new language policy to promote multilingualism in Fiji and the only document available is the 2013 Constitution which treats all languages as equal. However, what is needed is to actually have a structure in place or a curriculum to be designed to attest how multilingual studies need to be carried out. No expert advice has been sought in this field as the Ministry of Education is yet to develop a language policy.

6. 'There are a number of factors, such as changing attitude of the state and communities, availability of trained teachers and suitable teaching material that will undoubtedly affect the development of multilingual education. The Ministry of Education has the following six-fold responsibilities:

- $\quad$ Sponsoring multilingual teachers,

- Developing techniques and methods of multilingual education,

- $\quad$ Acquiring suitable teaching materials (written texts, tapes, films, pictures, photographs),

- Facilitating community participation (parents and the community should know why multilingualism is useful),

- $\quad$ Providing special service to linguistically disadvantaged children, and

- $\quad$ Redrawing the curriculum (initially the primary curriculum) possibly as a major donor-assisted project' (Fiji Island Education Commission Report, 2000, p. 300).

To date very little effort has been made and the six-fold responsibilities listed above have not been met yet. It seems that the Ministry of Education has not treated multilingual education with priority that has caused an imbalance with the languages in Fiji.

\section{Conclusion}

Language Policy and Planning (LPP) is an emerging field in particular for the Pacific region. Future research should look at how the language policies in Fiji have or have not been able to work out in practice and provide suggestions on how new policies will improve the imbalance of languages in a pluralistic Fiji. Even though the Fiji Island Education Commission Report was published in 2000, the insights provided 19 years ago are still valid and useful in the field of LPP. Chapter 18 of the report titled "Learning Languages Together" by Subramani includes discussion on Language Policy, Narratives on Language, Language Planning and Multilingualism and Reconciliation. The chapter 13 titled 'Other Ethnic Groups' written by Dr. Helen Tavola looks at the pragmatic approach versus cultural preservation as well as the minority groups which includes Part-Europeans, Rotumans, the Banaban, Chinese and Melanesian communities, speakers of Urdu, Tamil, Telegu and the people of Kioa.

Both of these chapters explain language issues faced in Fiji since the 1969 Education Commission report at length. The observations made or the narratives collected during the consultation process were independent as the members travelled throughout the country gathering information for several months before the compilation. Therefore, studying these two chapters or other chapters as well will provide a direction for the research methods to be used as well as assist in the research design of a study on LPP in Fiji. It will be worth investigating the reasons why the recommendations of the reports were not taken up by successive governments. On a similar note, due to the coup culture in Fiji, there have been a number of interim governments and policies or measures taken 
by them have also impacted the language of education. Therefore, all these have impacted the way language is being used in Fiji which needs to be studied comprehensively. Moreover, Ball (2010) states 'language death is a concern among speakers themselves, and adults all across the Pacific complain that young people 'don't know their language any more', usually blaming English. While such pronouncements may overstate the seriousness of the problem and reflect in part each generation's 'disapproval of any change among the young, the anxiety is genuinely felt and not entirely ill-founded'. Therefore, this paper has highlighted language issue(s) Fiji has been facing over decades as well as outlined the LPP status of the nation. In Fijian society the growing concern for language maintenance and loss entails an expeditious research in Language policy and planning which this paper sets as future implication for research.

\section{References}

Ball, M. J. (Ed.). (2010). The Routledge handbook of sociolinguistics around the world: a handbook. Routledge. https://doi.org/10.4324/9780203869659

Cummins, J. (1986). Empowering minority students: A framework for intervention. Harvard Educational Review, 56(1), 18-36. https://doi.org/10.17763/haer.56.1.b327234461607787

Fiji Education Commission. (1969). Education for Modern Fiji: Report of the Fiji Education Commission, 1969. Government Printer, South Africa. Forces of English: the Case of Iceland. Language Policy, 5, 293-312.

Fiji Islands Education Commission Report. (2000). Learning Together: Directions for Education in the Fiji Islands. Report of the Fiji Islands Education Commission/Panel. Suva. Government of Fiji. Ministry of Education.

Geraghty, P. (1984). Language policy in Fiji and Rotuma. Duivosavosa: Fiji's Languages-their use and their future. Fiji Museum Bulletin, 8, 32-84.

Hilmarsson-Dunn, A. M. (2006). Protectionist Language Policies in the face of the forces of English. The case of Iceland. Language Policy, 5(3), 295-314. https://doi.org/10.1007/s10993-006-9027-2

Mangubhai, F. (2002). Language-in-education policies in the South Pacific: Some possibilities for consideration. Journal of Multilingual and Multicultural Development, 23(6), 490-511. https://doi.org/10.1080/ 01434630208666482

Mangubhai, F., \& Mugler, F. (2003). The language situation in Fiji. https://doi.org/10.1080/14664200308668058

Mugler, F. (1996). Vernacular'language teaching in Fiji. Pacific languages in education, 273-86.

Mugler, F., \& Lynch, J. (1996). Language and education in the Pacific. In F. Mugler, \& J. Lynch (Eds.), Pacific languages in education (pp. 1-9). Suva: Institute of Pacific Studies, The University of South Pacific.

Nicholls, L. (2014). What is the socio-linguistic context for teaching English writing to senior high school students in Fiji?: a thesis completed in fulfilment of the requirements for the degree of Master of Philosophy (Humanities and Social Sciences) in Second Language Teaching, Massey University, Palmerston North, New Zealand (Doctoral dissertation, Massey University).

Perry Jr, F. L. (2011). Research in applied linguistics: Becoming a discerning consumer. Routledge. https://doi.org/10.4324/9780203839027

Roberts, S. (2007). A Critical Analysis of the Current Status of the Fijian Language. Independent Study Project (ISP) Collection, 216.

Shameem, N. (2002). Multilingual proficiency in Fiji primary schools. Journal of Multilingual and Multicultural Development, 23(5), 388-407. https://doi.org/10.1080/01434630208666476

Shrestha, P. (2008). Book Review: Language Planning and Policy in the Pacific, Fiji. The Philippines and Vanuatu by Richard B. Baldauf, Jr. and Robert B. Kaplan. Language Policy, 7(4), 369-371. https://doi.org/10.1007/s10993-007-9057-4

\section{Copyrights}

Copyright for this article is retained by the author(s), with first publication rights granted to the journal.

This is an open-access article distributed under the terms and conditions of the Creative Commons Attribution license (http://creativecommons.org/licenses/by/4.0/). 